
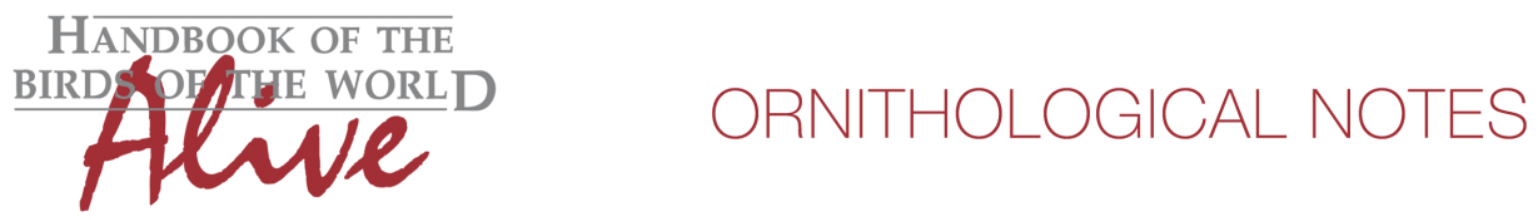

\title{
Notes on the vocalizations of Spotted Nutcracker (Nucifraga caryocatactes)
}

\section{Peter Boesman}

In the following we briefly analyze and compare voice of the different races of Spotted Nutcracker (Nucifraga caryocatactes). We also try to quantify the extent of any vocal differences using the criteria proposed by Tobias et al. (2010), as a support for taxonomic review. We have made use of sound recordings available on-line from Xeno Canto (XC).

Most common vocalization is a drawn-out harsh note.

\section{Some examples:}

caryocatactes: longest in length and rattling pace very high (inaudible)

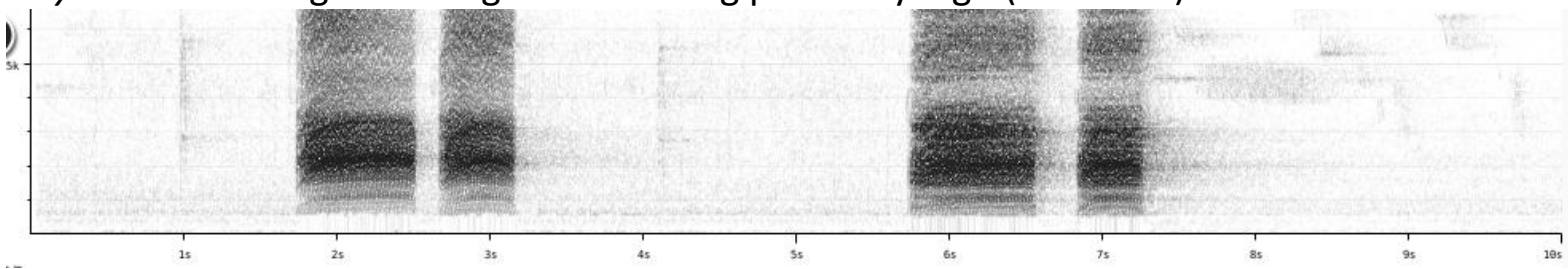

macrorhynchos: seemingly shorter duration on average

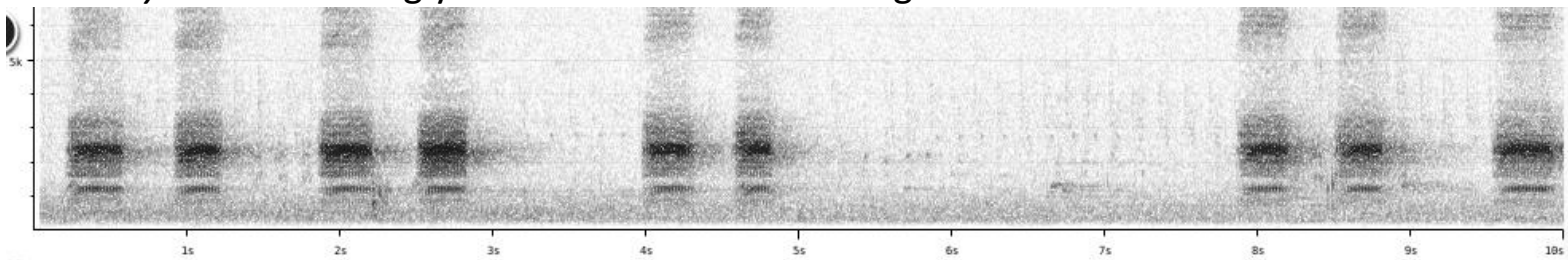

macella: similar in length to previous, but slightly higher-pitched and notably slower rattling pace (audible, sounding "krrrrrrrr")

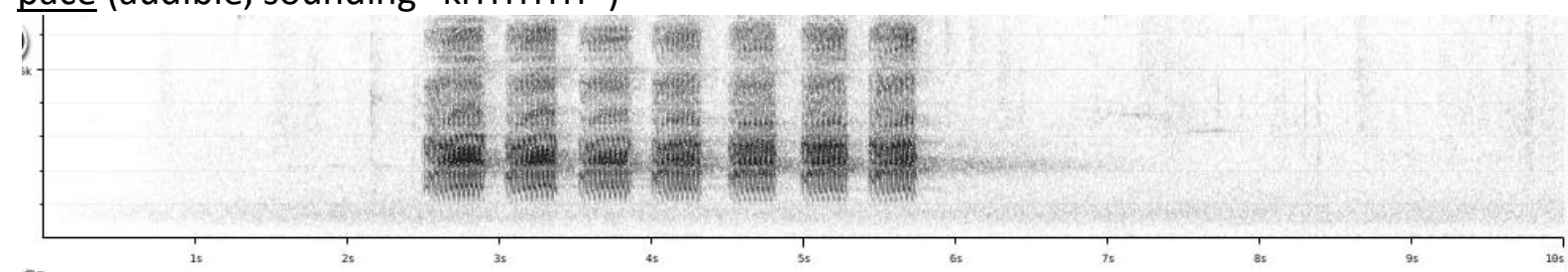

owstoni: only a single recording located, but again slow rattling pace

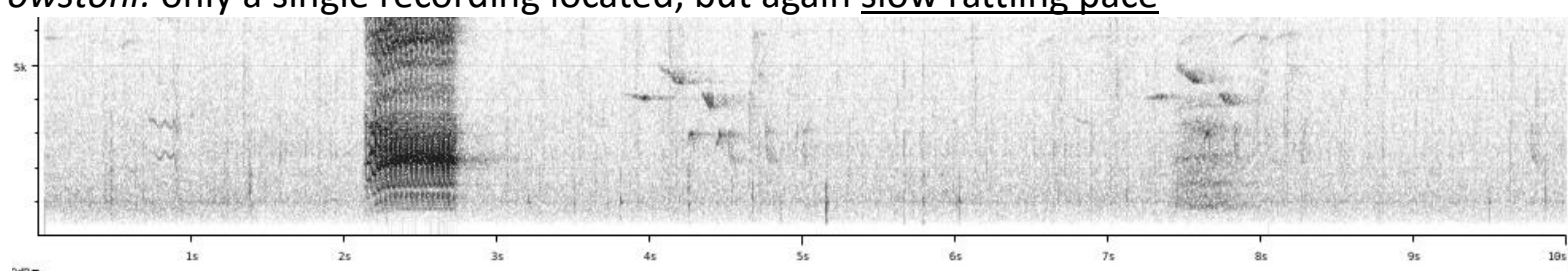

All races have additional vocalisations, but sample size of these is too small to determine whether there are true differences in vocabulary.

It would thus seem that the morphologically distinct "hemispila group" (also with interdicta, macella and owstoni) can be identified vocally from the "nominate group" (with remaining races). 

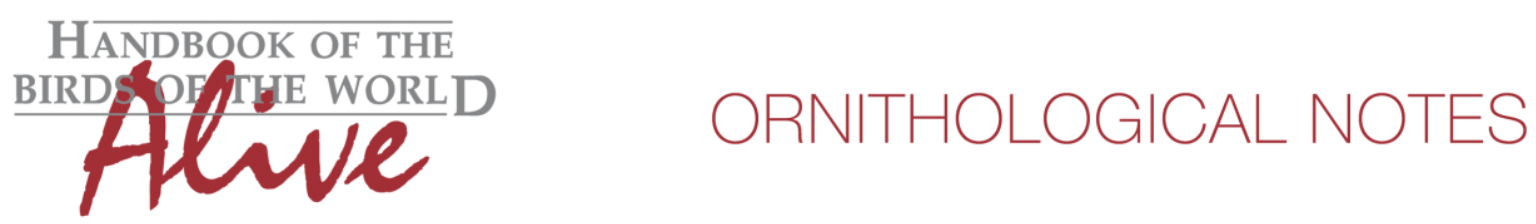

The main vocal difference seems to be the rattling pace of the harsh call note.

We have measured the period (duration between two consecutive notes) with following results:

'nominate group':

Rattling period: $0.017-0.023 \mathrm{~s}$ ( $n=6$, of diverse countries)

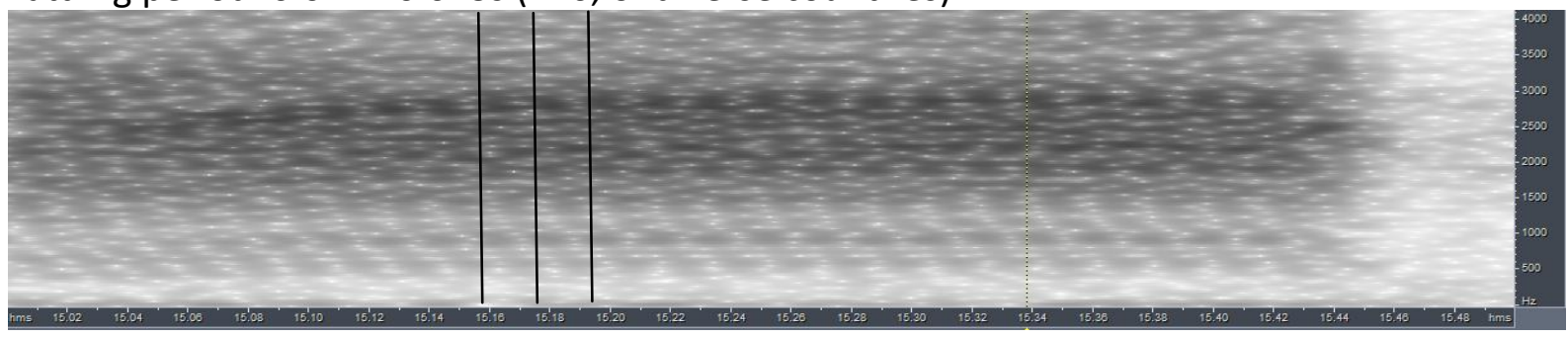

'hemispila group':

Rattling period: $0.032-0.042 \mathrm{~s}$ ( $n=8$, of diverse countries including Taiwan)

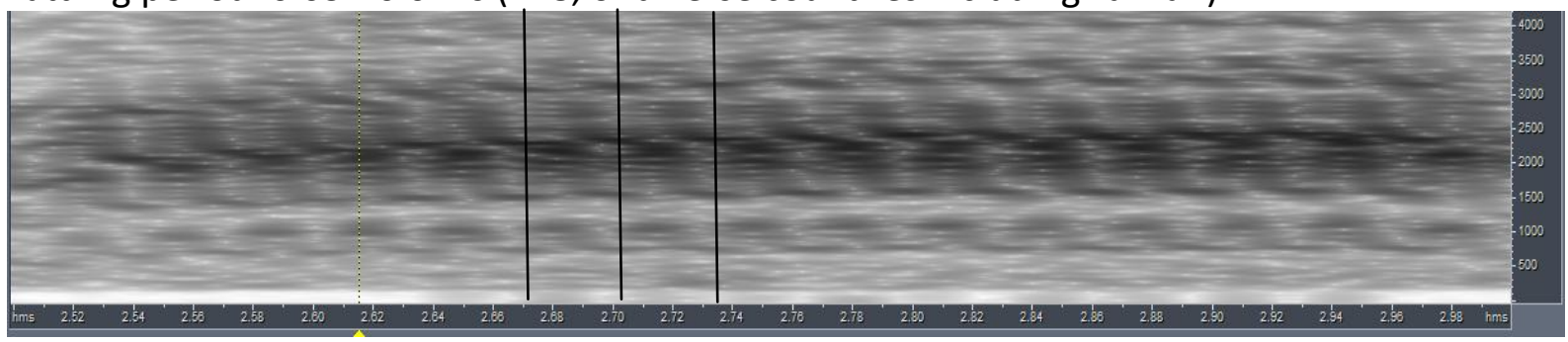

These quantified differences result in a total vocal score of 3.

This note was finalized on 27th January 2016, using sound recordings available on-line at that moment. We would like to thank in particular the many sound recordists who placed their recordings for this species on XC.

\section{References}

Tobias, J.A., Seddon, N., Spottiswoode, C.N., Pilgrim, J.D., Fishpool, L.D.C. \& Collar, N.J. (2010). Quantitative criteria for species delimitation. Ibis 152(4): 724-746.

\section{Recommended citation}

Boesman, P. (2016). Notes on the vocalizations of Spotted Nutcracker (Nucifraga caryocatactes). HBW Alive Ornithological Note 208. In: Handbook of the Birds of the World Alive. Lynx Edicions, Barcelona. (retrieved from http://www.hbw.com/node/932157 on 2 September 2016). 